\title{
The Amsterdam Declaration on Graves' Orbitopathy
}

\author{
Petros Perros
}

Department of Endocrinology, Royal Victoria Infirmary, Newcastle upon Tyne, UK

\section{Why Is There a Need for a Declaration on Graves' Orbitopathy?}

For decades, clinicians who manage patients with Graves' orbitopathy (GO) have been anticipating the emergence of new effective therapies for the management of this condition. That dream has yet to come true, but it has become apparent that conventional treatments such as steroids and surgery, when applied at the appropriate time and by centres that have accumulated sufficient experience and expertise, can lead to very satisfactory results.

No idea is ever entirely new and the Amsterdam Declaration is no exception. Its predecessor is the Saint Vincent Declaration for diabetes, signed exactly 20 years earlier [1]. Like diabetes, GO is responsible for prolonged ill health, the available services are variable [2-5], and there is a strong feeling that outcomes can, and should improve. The objectives of the Amsterdam Declaration are to improve care of patients with GO and to prevent it occurring in patients who are at risk. There are specific 5 year targets focusing on raising awareness, defining pathways of care, supporting centres of excellence, establishing audit and monitoring mechanisms, and implement measures to reduce the incidence and morbidity of the disease.

\section{Wy Is the Declaration Called the Amsterdam Declaration?}

The concept of a declaration on Graves' Orbitopathy was conceived in April 2009 by some members of EUGOGO. The 10th International Symposium on Graves' Orbitopathy, scheduled to take place in Amsterdam at the end of October 2009, was fast approaching and it seemed entirely appropriate to announce and sign the declaration at that meeting. 


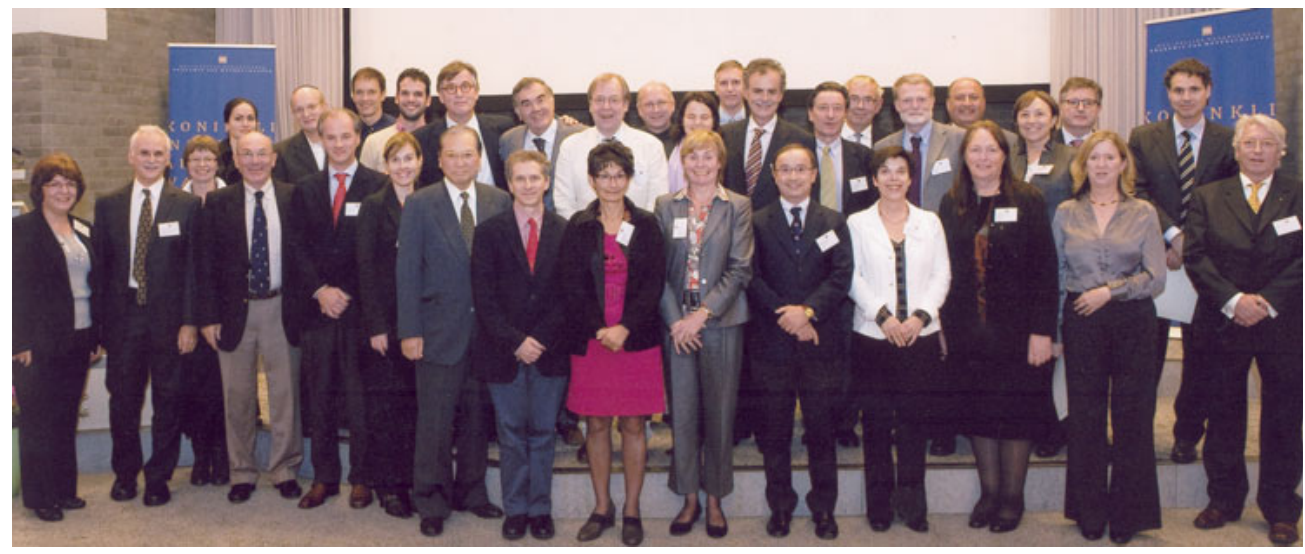

Fig. 1. Signatories of the Amsterdam Declaration on Graves' Orbitopathy, October 30th 2009.

\section{What Is the Text of the Amsterdam Declaration?}

The official document is given in appendix 1 .

\section{Who Signed the Amsterdam Declaration?}

Having formulated the Amsterdam Declaration, EUGOGO canvassed for support from professional societies and thyroid patient-led organizations. The response surpassed all expectations. The Amsterdam Declaration was signed at the Royal Netherlands Academy of Sciences in Amsterdam on the 30th October 2009 (fig. 1). By early 2010, the Amsterdam Declaration was supported by 82 organizations including all 4 international thyroid sister associations, 15 international professional societies, 44 national professional societies and 23 patient-led organizations (appendix 2). There can be no doubt that there is a global support among the thyroid community for the Amsterdam Declaration. The real challenge is how to turn a wish list into results.

\section{Can Other Societies Still Sign the Declaration?}

Other learned societies and patient associations involved in GO are very welcome to sign the declaration. To become a cosignatory please contact the secretary of EUGOGO Mario Salvi in Milano, Italy, via E-mail (mario@mariosalvinet.it). The more cosignatories, the higher the chance that the objectives of the Amsterdam Declaration will be reached! 


\section{Appendix 1: Graves' Orbitopathy: Improving Outcomes for Thyroid Eye Disease. The Amsterdam Declaration}

Graves' orbitopathy affects hundreds of thousands of people in the world every year. It causes pain, discomfort, double vision, disfigurement and sometimes blindness. People suffering with Graves' orbitopathy have a poor quality of life and long-term psychosocial morbidity. The quality of care received by the majority of people affected by this condition can be improved. Conventional treatments are effective when used appropriately and by centres with expertise. Not all patients are offered effective treatments either because most are not referred early or not at all. People at high risk of developing Graves' orbitopathy can be identified and effective risk management can potentially lessen the severity of the disease.

The care of people with Graves' orbitopathy can be improved vastly by making centres of excellence more accessible to them.

In October 2009, international experts on Graves' orbitopathy, representatives of professional organisations and patient representatives met in Amsterdam and unanimously agreed on the following:

Health care providers and professional organisations should recognise the need to improve the care of people with Graves' orbitopathy and support plans for implementing better care and prevention.

The general objectives are:

- to minimise the morbidity associated with Graves' orbitopathy and improve the patients' experience and quality of life;

- prevent the development of Graves' orbitopathy in people at high risk.

The 5-year targets are:

- raise awareness of this condition among health care professionals and managers;

- establish pathways of referral and care;

- support existing centres of excellence in management of this condition;

- create new centres of excellence in localities where they are lacking;

- establish audit and monitoring mechanisms of quality assurance of provision of care to people with Graves' orbitopathy;

- implement measures to reduce the incidence and morbidity of the disease by

- halving the time from presentation to diagnosis

- halving the time from diagnosis to referral to a centre of excellence

- appropriate management of thyroid dysfunction including use of radioiodine

- vigorous anti-smoking measures in patients at risk of or with Graves' orbitopathy

- improve the existing research networks and develop further international collaborative research. 


\section{Appendix 2: Signatories of the Amsterdam Declaration}

International Professional Organisations

Academia Ophthalmologica Europea

Academia Ophthalmologica Internationalis

American Thyroid Association

Asia-Oceania Thyroid Association

Asia Pacific Society of Ophthalmic Plastic and Reconstructive Surgery

Endocrine Society

European Association for Vision and Eye Research (EVER)

European Group on Graves' Orbitopathy

European Society of Endocrinology

European Society of Orbital Plastic Reconstructive Surgery

European Thyroid Association

Iberico-American Society of Ophthalmic Plastic and Orbital Surgery

International Thyroid Eye Disease Study Group

Latin-American Thyroid Society

World Society of Pediatric Ophthalmology and Strabismus (WSPOS)

\section{International thyroid patient association}

Thyroid Federation International

\section{National professional organisations}

All India Ophthalmological Society

American Association of Clinical Endocrinologists

Argentina Council of Ophthalmology (Consejo Argentino de Oftalmologia)

Argentina Society of Ophthalmology (SAO)

Belgian Endocrine Society

Belgian Thyroid Club

Bielschowsky-Gesellschaft für Schielforschung und Neuroophthalmologie

British Oculoplastic Surgery Society

British Thyroid Association

Chinese Society of Ophthalmology

Cyprus Endocrine Society

Danish Thyroid Association

Dutch Endocrine Society

Finnish Endocrine Society

French Endocrine Society

French Society of Ophthalmic Plastic Reconstructive and Aesthetic Surgery

German Endocrine Society 
German Thyroid Board

German Society of Ophthalmology (Deutsche Ophthalmologische Gesellschaft)

Hellenic Endocrine Society

Hellenic Society of Ophthalmic Plastic and Reconstructive Surgery

Irish Endocrine Society

Italian Association of Medical Endocrinologists (Associazione Medici

Endocrinologi)

Italian Society of Endocrinology

Italian Society of Ophthalmic Plastic Surgery (Società Italiana di Chirurgia Oftalmoplastica, SICOP)

Italian Thyroid Association

Japan Thyroid Association

Japanese Society of Ophthalmology

Macedonian Endocrine Association

Oculoplastic Association of India

Ophthalmological Society of Portorico (Sociedad Puertorriqueña de Oftalmología)

Philippine Society of Ophthalmic Plastic and Reconstructive Surgery (PSOPRS)

Philippine Academy of Ophthalmology (PAO)

Polish Thyroid Society

Romanian Society for Endocrinology

Royal College of Ophthalmologists (UK)

Serbian Endocrine Society

Slovak Endocrine Society

Società Oftalmologica Italiana

Society for Endocrinology (UK)

South African Society of Oculoplastic Surgeons

Spanish Society of Ophthalmic Plastic and Orbital Surgery (Sociedad Espanola de

Cirurgia Plastica Ocular y Orbitaria, SECPOO)

Swiss Endocrine and Diabetes Society (SGED/SSED)

Turkish Society for Endocrinology and Metabolism

\section{National thyroid patient organisations}

Association "Vivre sans Thyroïde"

British Thyroid Foundation

Finnish Thyroid Foundation

Georgian Union of Diabetes and Endocrine Associations (GUDEAS)

Italian Thyroid Patient Association

La Asociación Mexicana de Tiroides

Nederlandse Vereniging van Graves' patienten

Norsk Thyreoideaforbund

Ohne Schilddrüse leben e.V. 
Schilddrüsen-Liga Deutschland e.V.

Schildklierstichting Nederland (Thyroid Patients Organization of the Netherlands)

Svenska Sköldkörtel Föreningen.

The Australian Thyroid Foundation Ltd.

Thyroid Australia

Thyroid Eye Disease charitable trust (UK)

Thyreoidea Landsforeningen

Instituto da Tiroide

Japan Thyroid Foundation

Thyroid Foundation of Canada / La Fondation canadienne de la Thyroïde

Thyroid Foundation of St. Petersburg

United States of America Graves' Disease Foundation

Verein Schilddrüsengruppe Schweiz

\section{References}

1 Krans HMJ, Porta N, Keen H: Diabetes Care and Research in Europe. The St Vincent Declaration Action Programme. Copenhagen, World Health Organization Regional Office for Europe, 1992.

$>2$ Perros P, Baldeschi L, Boboridis K, Dickinson AJ, Hullo A, Kahaly GJ, Kendall-Taylor P, Krassas GE, Lane CM, Lazarus JH, Marcocci C, Marino M, Mourits MP, Nardi M, Orgiazzi J, Pinchera A, Pitz S, Prummel MF, Wiersinga WMA: A questionnaire survey on the management of Graves' orbitopathy in Europe. Eur J Endocrinol 2006;155:207-211.
Ramos HE, Diehl LA, Camacho CP, Perros P, Graf $\mathrm{H}$ : Management of Graves' orbitopathy in Latin America: an international questionnaire study compared with Europe. Clin Endocrinol (Oxf) 2008;69: 951-956.

Estcourt S, Hickey J, Perros P, Dayan C, Vaidya B: The patient experience of services for thyroid eye disease in the United Kingdom: results of a nationwide survey. Eur J Endocrinol 2009;161:483-487.

Estcourt S, Vaidya B, Quinn A, Shepherd M: The impact of thyroid eye disease upon patients' wellbeing: a qualitative analysis. Clin Endocrinol (Oxf) 2008;68:635-639. 